\title{
Cassia tora L. (Jue-ming-zi) has anticancer activity in TCA8113 cells in vitro and exerts anti-metastatic effects in vivo
}

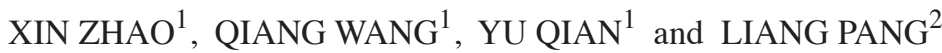 \\ ${ }^{1}$ Department of Biological and Chemical Engineering, Chongqing University of Education, Chongqing 400067; \\ ${ }^{2}$ Department of Oral and Maxillofacial Surgery, the Affiliated Hospital of Stomatology, \\ Chongqing Medical University, Chongqing 401147, P.R. China
}

Received October 5, 2012; Accepted December 21, 2012

DOI: $10.3892 / 01.2012 .1097$

\begin{abstract}
Cassia tora L. (Jue-ming-zi) is a traditional Chinese medicine widely used in East Asia. The in vitro anticancer effects of Jue-ming-zi were evaluated in TCA8113 human tongue carcinoma cells using a 3-(4,5-dimethyl-2-thiazolyl)-2,5-diphenyltetrazolium bromide (MTT) assay. At a concentration of $1.0 \mathrm{mg} / \mathrm{ml}$, Cassia tora $\mathrm{L}$. inhibited the growth of TCA8113 cells by $72 \%$; this inhibiton was greater than that by 0.5 and $0.25 \mathrm{mg} / \mathrm{ml}$ Cassia tora $\mathrm{L}$. (43 and 16\%, respectively). To elucidate the inhibitory mechanisms underlying the anticancer effect of Cassia tora L. in cancer cells, the expression of genes associated with apoptosis, inflammation and metastasis were measured using RT-PCR and western blot analysis. Cassia tora L. significantly induced apoptosis in cancer cells $(\mathrm{P}<0.05)$ by upregulating Bax, caspase-3 and caspase-9, and by downregulating Bcl-2. The expression of genes associated with inflammation, including NF- $\kappa B$, iNOS and COX-2, was significantly downregulated $(\mathrm{P}<0.05)$ by Cassia tora $\mathrm{L}$., demonstrating its anti-inflammatory properties. Cassia tora L. also exerted a significant anti-metastatic effect on cancer cells as demonstrated by decreased mRNA expression of matrix metalloprotease (MMP) genes and increased expression of tissue inhibitors of metalloproteinases (TIMPs), and as confirmed by the inhibition of induced tumor metastasis induced in 26-M3.1 colon cells in $\mathrm{BALB} / \mathrm{c}$ mice. Our results demonstrated that Cassia tora L. exhibited the most potent in vitro anticancer effects, induced apoptosis, had anti-inflammatory activities and exerted
\end{abstract}

Correspondence to: Ms. Liang Pang, Department of Oral and Maxillofacial Surgery, the Affiliated Hospital of Stomatology, Chongqing Medical University, Songshi Northroad, Yubei District, Chongqing 401147, P.R. China

E-mail: foods@live.cn

Dr Yu Qian, Department of Biological and Chemical Engineering, Chongqing University of Education, No.9, Xuefu Main Street, Nan'an District, Chongqing City, 400067, P.R. China

E-mail: qianyubaby@126.com

Key words: Cassia tora L., anticancer, apoptosis, anti-metastasis in vivo anti-metastatic effects. Additionally, the anticancer, anti-inflammatory and anti-metastatic effects of the higher Cassia tora $\mathrm{L}$. concentrations were stronger compared with those of the lower Cassia tora $\mathrm{L}$. concentrations tested.

\section{Introduction}

The Chinese herb, Jue-ming-zi, is the seed of the plant Cassia tora L. (Leguminosae), and has been used as a laxative and a tonic, as well as being a popular health tea drink. The commercial products of Cassia tora $\mathrm{L}$. include both unroasted and roasted samples, and the laxative effect was found to be higher in unroasted compared with roasted Cassia tora $\mathrm{L}$ samples (1).

Pharmaceutical research has concentrated on the beneficial activities of Cassia tora L. such as its liver-protection, anti-aging, anticancer and antioxidant effects (2-5). Cassia tora L. contains anthraquinones, naphtho-pyrones, fatty acids, amino acids and inorganic elements (6). Types of Cassia tora L. with a high anthraquinone content, such as chrysophanol, physcion and obtusin, may help to decrease blood lipid levels (7).

The induction of apoptosis in cancer cells is initially identified by morphological changes including cell shrinkage, membrane blebbing, chromatin condensation and nuclear fragmentation (8). Apoptosis is an important defense against cancer. The process involves the elimination of potentially harmful cells. Many diseases have been associated with dysregulated apoptotic processes, ultimately leading to the inhibition of cell death and the propagation of diseases such as cancer (9).

Caspases are central components of the apoptotic response. Caspase-9 is an apical isoform involved in mitochondria-dependent apoptosis. This factor primarily activates caspase-3, which then serves as a gateway for the activation of downstream caspases (10). Nuclear factor- $\kappa \mathrm{B}$ (NF- $\kappa \mathrm{B})$ is involved in the inhibition of apoptosis, stimulation of cell proliferation, inflammation, immune response and tumorigenesis. Activation of NF- $\mathrm{BB}$ generally prevents apoptosis. Expression of inducible nitric oxide synthase (iNOS) and cyclooxygenase (COX)-2, two genes regulated by NF- $\kappa \mathrm{B}$, are induced by inflammation and are frequently overexpressed in cancer cells. Increased NF- $\mathrm{KB}$ activity that is localized in the 
Table I. Sequences of reverse transcription-polymerase chain reaction (RT-PCR) primers used in this study.

\begin{tabular}{|c|c|}
\hline Gene name & Sequence \\
\hline $\operatorname{Bax}$ & $\begin{array}{l}\text { Forward: 5'-AAG CTG AGC GAG TGT CTC CGG CG-3' } \\
\text { Reverse: 5'-CAG ATG CCG GTT CAG GTA CTC AGT C-3' }\end{array}$ \\
\hline Bcl-2 & $\begin{array}{l}\text { Forward: 5'-CTC GTC GCT ACC GTC GTG ACT TGG-3' } \\
\text { Reverse: 5'-CAG ATG CCG GTT CAG GTA CTC AGT C-3' }\end{array}$ \\
\hline Caspase-3 & $\begin{array}{l}\text { Forward: 5'-CAA ACT TTT TCA GAG GGG ATC G-3' } \\
\text { Reverse: 5'-GCA TAC TGT TTC AGC ATG GCA-3' }\end{array}$ \\
\hline Caspase-9 & $\begin{array}{l}\text { Forward: 5'-GGC CCT TCC TCG CTT CAT CTC-3' } \\
\text { Reverse: 5'-GGT CCT TGG GCC TTC CTG GTA T-3' }\end{array}$ \\
\hline NF-кB & $\begin{array}{l}\text { Forward: 5'-CAC TTA TGG ACA ACT ATG AGG TCT CTG G-3' } \\
\text { Reverse: 5'-CTG TCT TGT GGA CAA CGC AGT GGA ATT TTA GG-3' }\end{array}$ \\
\hline $\mathrm{I} \kappa \mathrm{B}-\alpha$ & $\begin{array}{l}\text { Forward: 5'-GCT GAA GAA GGA GCG GCT ACT-3' } \\
\text { Reverse: 5'-TCG TAC TCC TCG TCT TTC ATG GA-3' }\end{array}$ \\
\hline iNOS & $\begin{array}{l}\text { Forward: 5'-AGA GAG ATC GGG TTC ACA-3' } \\
\text { Reverse: 5'-CAC AGA ACT GAG GGT ACA-3' }\end{array}$ \\
\hline $\mathrm{COX}-2$ & $\begin{array}{l}\text { Forward: 5'-TTA AAA TGA GAT TGT CCG AA-3' } \\
\text { Reverse: 5'-AGA TCA CCT CTG CCT GAG TA-3' }\end{array}$ \\
\hline MMP-2 & $\begin{array}{l}\text { Forward: 5'-CTT CTT CAA GGA CCG GTT CA-3' } \\
\text { Reverse: 5'-GCT GGC TGA GTA CCA GTA-3' }\end{array}$ \\
\hline MMP-9 & $\begin{array}{l}\text { Forward: 5'-TGG GCT ACG TGA CCT ATG AC-3' } \\
\text { Reverse: 5'-GCC CAG CCC ACC TCC ACT CC-3' }\end{array}$ \\
\hline TIMP-1 & $\begin{array}{l}\text { Forward: 5'-GTC AGT GAG AAG CAA GTC GA-3' } \\
\text { Reverse: 5'-ATG TTC TTC TCT GTG ACC CA-3' }\end{array}$ \\
\hline TIMP-2 & $\begin{array}{l}\text { Forward: 5'-TGG GGA CAC CAG AAG TCA AC-3' } \\
\text { Reverse: 5'-TTT TCA GAG CCT TGG AGG AG-3' }\end{array}$ \\
\hline GAPDH & $\begin{array}{l}\text { Forward: 5'-CGG AGT CAA CGG ATT TGG TC-3' } \\
\text { Reverse: 5'-AGC CTT CTC CAT GGT CGT GA-3' }\end{array}$ \\
\hline
\end{tabular}

nucleus is particularly found in cells where there is abundant expression of iNOS and COX-2 (11).

A previous epidemiological study demonstrated that chronic inflammation predisposes individuals to various types of cancer (12). Hallmarks of inflammation-related cancers include the presence of inflammatory cells and mediators in tumor tissues, tissue remodeling and angiogenesis similar to that seen during chronic inflammatory responses, and tissue repair. The study of mechanisms underlying inflammation-related cancer has focused on the early stages of cancer; however, inflammatory mediators and cells are also involved in the migration, invasion and metastasis of malignant cells (13). Metastasis is the leading cause of mortality among cancer patients, and involves the spread of cancer from a primary site and the formation of new tumors in distant organs. Matrix metalloproteases (MMPs) are important in numerous physiological and pathological processes including embryonic development, morphogenesis, reproduction, tissue remodeling, arthritis, cardiovascular disease and metastasis (14). MMP activity is inhibited by specific endogenous tissue inhibitors of metalloproteinases (TIMPs) (15). To prevent the majority of cancer types, improved treatments for metastasis are required $(16,17)$.
Previously, Cassia tora L. demonstrated strong in vitro anticancer effects in JTC-26 human cervical cancer cells (6). In the present study, we further examined the anticancer and anti-metastatic effects of Cassia tora L.; Cassia tora L. was administered to human tongue carcinoma TCA8113 cells and the molecular mechanisms underlying the anticancer effects of the Cassia tora L. were studied. Changes in activities of Cassia tora L. at different concentrations were evaluated and their anti-metastatic effects were assessed in mice with tumors propagated by 26-M3.1 colon carcinoma cells.

\section{Materials and methods}

Preparations of Cassia tora L. Cassia tora L. (Jue-ming-zi) was purchased from Yunnan Baiyao Group Co. Ltd. (Kunming, China) and stored at $-80^{\circ} \mathrm{C}$ and freeze-dried to produce a powder. A 20 -fold volume of methanol was added to the powdered sample and extracted twice by stirring overnight. The methanol extract was evaporated using a rotary evaporator (N-1100; Eywla; Tokyo, Japan), concentrated and then dissolved in dimethylsulfoxide (DMSO; Amresco, Solon, OH, USA) to adjust to the stock concentration $(20 \%$, $\mathrm{w} / \mathrm{v})$. 
Table II. Growth inhibition of human tongue carcinoma TCA8113 cells by different concentrations of Cassia tora L., as evaluated by a 3-(4,5-dimethylthiazol-2-yl)-2,5-diphenyltetrazolium bromide (MTT) assay.

OD540 (concentration of sample, $\mathrm{mg} / \mathrm{ml}$ )

Treatment

0.25

0.5

1.0

Control (untreated)

Cassia tora $\mathrm{L}$.

$0.417 \pm 0.008^{b}(16)$

$0.497 \pm 0.005^{\mathrm{a}}$

$0.283 \pm 0.010^{\mathrm{c}}(43)$

$0.139 \pm 0.007^{\mathrm{d}}(72)$

The values in parentheses are the inhibition rates $(\%) .{ }^{\mathrm{a}-\mathrm{d}}$ Mean values with different letters in the same column are significantly different $(\mathrm{P}<0.05)$ according to the Duncan's multiple range test.

Cancer cell preparation. Human tongue carcinoma TCA8113 cells obtained from the Shanghai Institute of Biochemistry and Cell Biology (SIBCB; Shanghai, China) were used in the experiments. The cells were cultured in Roswell Park Memorial Institute (RPMI)-1640 medium (Gibco Co., Birmingham, MI, USA) supplemented with $10 \%$ fetal bovine serum (FBS; Gibco Co.) and 1\% penicillin-streptomycin (Gibco Co.), at $37^{\circ} \mathrm{C}$ in a humidified atmosphere containing 5\% $\mathrm{CO}_{2}$ (model 311 S/N29035; Forma; Waltham, MA, USA). The medium was replaced two or three times each week.

\section{3-(4,5-dimethyl-2-thiazolyl)-2,5-diphenyltetrazolium}

bromide (MTT) assay. The anticancer effects of Cassia tora L. were assessed by an MTT assay. Human tongue carcinoma TCA8113 cells were seeded in a 96-well plate at a density of $2 \times 10^{4}$ cells $/ \mathrm{ml}$ and a volume of $180 \mu \mathrm{l} /$ well. Cassia tora $\mathrm{L}$. solution $(20 \mu \mathrm{l})$ was added at concentrations of $0.25,0.5$ and $1.0 \mathrm{mg} / \mathrm{ml}$, and then the cells were incubated at $37^{\circ} \mathrm{C}$ in $5 \%$ $\mathrm{CO}_{2}$ for $48 \mathrm{~h}$. An MTT solution $(200 \mu \mathrm{l} ; 5 \mathrm{mg} / \mathrm{ml}$; Amresco) was added and the cells were cultured for a further $4 \mathrm{~h}$ under the same conditions. Following removal of the supernatant, $150 \mu \mathrm{l}$ DMSO was added to each well and mixed for $30 \mathrm{~min}$. Subsequently, the absorbance of each well was measured with an enzyme-linked immunosorbant assay (ELISA) reader (model 680; Bio-Rad; Hercules, CA, USA) at $540 \mathrm{~nm}$ (18).

Measuring RNA expression using reverse transcriptionpolymerase chain reaction $(R T-P C R)$. Total RNA was isolated from human tongue carcinoma TCA8113 cells using TRIzol reagent (Invitrogen Life Technologies; Carlsbad, CA, USA) according to the manufacturer's instructions. The RNA was digested with RNase-Free DNase (Roche; Basel, Switzerland) for $15 \mathrm{~min}$ at $37^{\circ} \mathrm{C}$ and purified using an RNeasy kit (Qiagen; Hilden, Germany) according to the manufacturer's instructions. cDNA was synthesized from $2 \mu \mathrm{g}$ of the total RNA by incubation at $37^{\circ} \mathrm{C}$ for $1 \mathrm{~h}$ with AMV reverse transcriptase (GE Healthcare, Little Chalfont, UK) and random hexanucleotides ,according to the manufacturer's instructions. The sequences of the primers used to specifically amplify the genes of interest are listed in Table I. Amplification was performed in a thermal cycler (Eppendorf; Hamburg, Germany). The PCR products were separated in $1.0 \%$ agarose gels and visualized by ethidium bromide (EtBr) staining (19).
Protein extraction and western blot analysis. Total cell lysates were obtained with an extraction buffer as previously described by Choi et al (20). Protein concentrations were determined using a protein assay kit (Bio-Rad). For western blot analysis, aliquots of the lysate containing 30-50 $\mu \mathrm{g}$ of protein were separated by sodium dodecyl sulfate-polyacrylamide gel electrophoresis (SDS-PAGE) and then electrotransferred onto a nitrocellulose membrane (Schleicher and Schuell; Keene, NH, USA). The membranes were subjected to immunoblot analysis and the proteins were visualized by an enhanced chemiluminescence (ECL) method (GE Healthcare). The cell lysates were separated by $12 \%$ SDS-PAGE, transferred onto a polyvinylidene fluoride membrane (GE Healthcare), blocked with 5\% skimmed milk and incubated with the primary antibodies (dilution, 1:1,000). Antibodies against Bax, Bcl-2, iNOS and COX-2 were obtained from Santa Cruz Biotechnology, Inc. (Santa Cruz, CA, USA). Following incubation with horseradish peroxidase-conjugated secondary antibody at room temperature, immunoreactive proteins were detected using an ECL assay kit (GE Healthcare) according to the manufacturer's instructions. Bands in the blot were visualized using a LAS3000 luminescent image analyzer (Fujifilm Life Science; Tokyo, Japan).

Measuring lung metastasis following Cassia tora L. treatment in BALB/c mice bearing 26-M3.1 colon carcinoma cell tumors. 26-M3.1 colon carcinoma cells were obtained from Professor Yoon, Department of Food and Nutrition, Yuhan University (Bucheon, South Korea). These highly metastatic cells were maintained as monolayers in EMEM (Gibco Co.) supplemented with $7.5 \%$ FBS, a vitamin solution, sodium pyruvate, non-essential amino acids and L-glutamine (Gibco Co.). The cultures were maintained in a humidified atmosphere of $5 \% \mathrm{CO}_{2}$ at $37^{\circ} \mathrm{C}$. Experimental lung metastasis was induced by injecting colon 26-M3.1 cells into the lateral tail vein of 6-week-old female Balb/c mice (Experimental Animal Center of Chongqing Medical University; Chongqing, China) (21). Cassia tora L. solution (50, 100 or $200 \mathrm{mg} / \mathrm{kg}$ ) was subcutaneously injected into the mice, which were then intravenously inoculated with $26 \mathrm{M}-3.1$ cells $\left(2.5 \times 10^{4} /\right.$ mouse $)$ after 2 days. The mice were sacrificed after 2 weeks and the lungs were fixed in Bouin's solution (saturated picric acid: formalin: acetic acid; 15:5:1; v/v/v). The rate of metastasis was assessed by counting the number of lung tumor colonies using a digital camera (Canon D550; Canon, Inc.; Tokyo, Japan). 


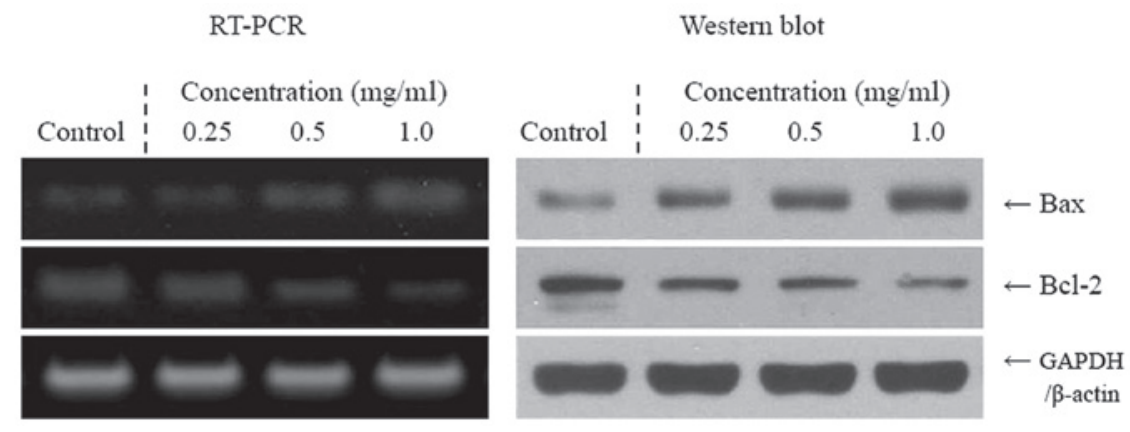

Figure 1. Effects of Cassia tora L. on the mRNA and protein expression of Bax and Bcl-2 in human tongue carcinoma TCA8113 cells.

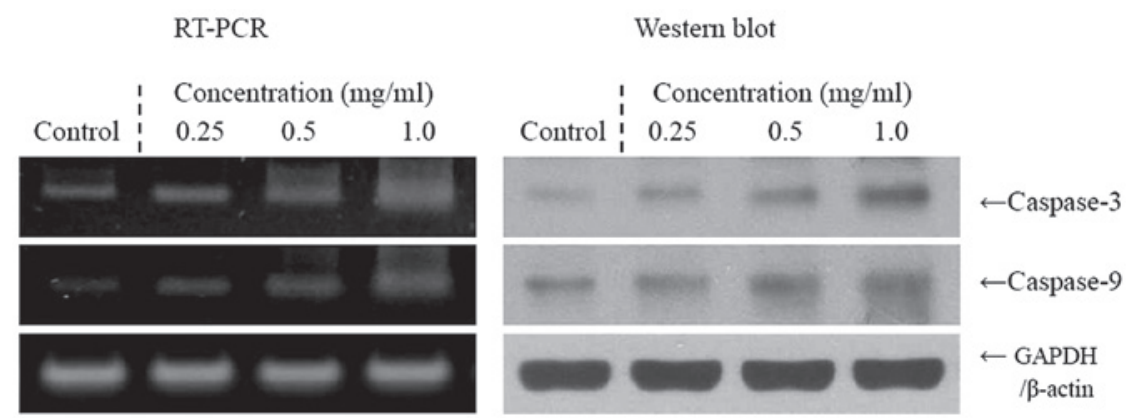

Figure 2. Effects of Cassia tora L. on the mRNA and protein expression of caspase-3 and -9 in human tongue carcinoma TCA8113 cells.

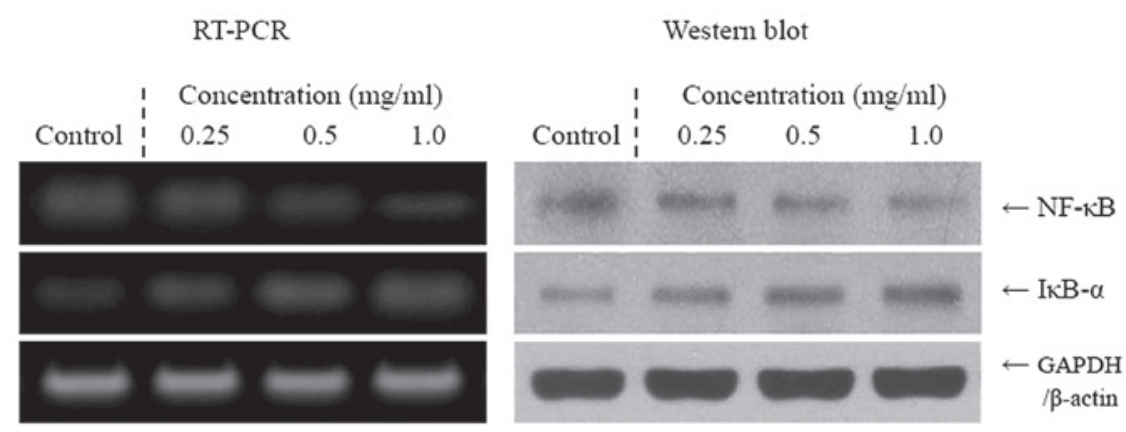

Figure 3. Effects of Cassia tora L. on the mRNA and protein expression of NF-кB and IкB- $\alpha$ in human tongue carcinoma TCA8113 cells.

The protocol for the animal experiments was approved by the Animal Ethics Committee of Chongqing Medical University.

Statistical analysis. Data are presented as the mean \pm standard deviation. Differences in the mean values of individual groups were assessed with a one-way analysis of variance (ANOVA) with a Duncan's multiple range test. $\mathrm{P}<0.05$ was considered to indicate a statistically significant difference. SAS software, version 9.1 (SAS Institute Inc.; Cary, NC, USA) was used for statistical analyses.

\section{Results}

In vitro anticancer effect of Cassia tora L. on TCA8113 cells. The anticancer effect of Cassia tora L. on TCA8113 cells was evaluated using an MTT assay. The growth inhibitory rates of human tongue carcinoma TCA8113 cells treated with the different concentrations of Cassia tora L. are demonstrated in Table II. When Cassia tora L. solution was administered to TCA8113 cells, the growth inhibitory rates observed with concentrations of $0.25,0.5$ and $1.0 \mathrm{mg} / \mathrm{ml}$ were 16,43 and $72 \%$, respectively $(\mathrm{P}<0.05)$. These results demonstrated that Cassia tora L. has a significant anti-proliferative effect on TCA8113 cells. In addition, the higher the concentration of Cassia tora L., the stronger the anticancer effect.

Apoptosis-related gene expression of Bax, Bcl-2 and caspases. To elucidate the mechanisms underlying the inhibition of cancer cell growth by the Cassia tora L., the expression of Bax, Bcl-2, and caspase-3 and -9 was measured in human tongue carcinoma TCA8113 cells by RT-PCR and western blot analyses after a 48-h incubation with different concentrations of Cassia tora L. solution. As demonstrated in Fig. 1, the expression of pro-apoptotic Bax and anti-apoptotic Bcl-2 demonstrated significant changes in the presence of $1.0 \mathrm{mg} / \mathrm{ml}$ Cassia tora $\mathrm{L}$. These results suggest 


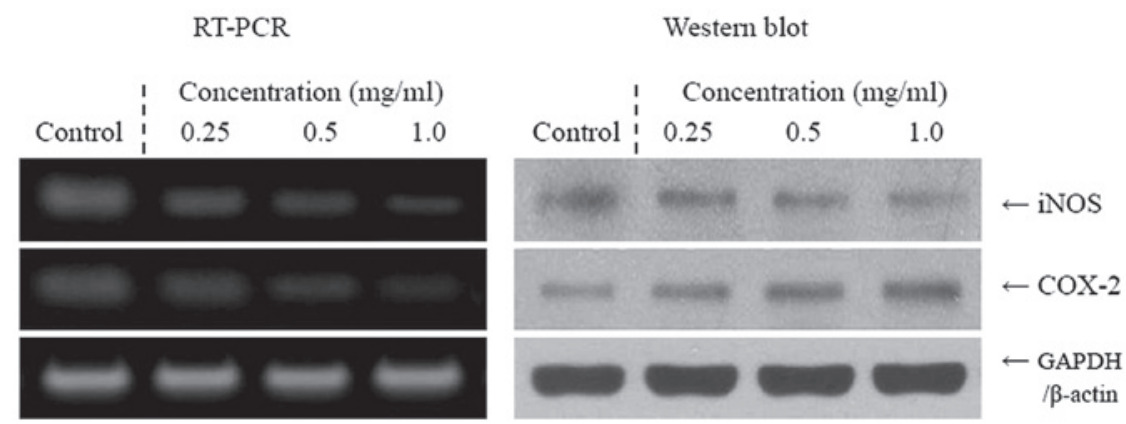

Figure 4. Effects of Cassia tora L. on the mRNA and protein expression of iNOS and COX-2 in human tongue carcinoma TCA8113 cells.

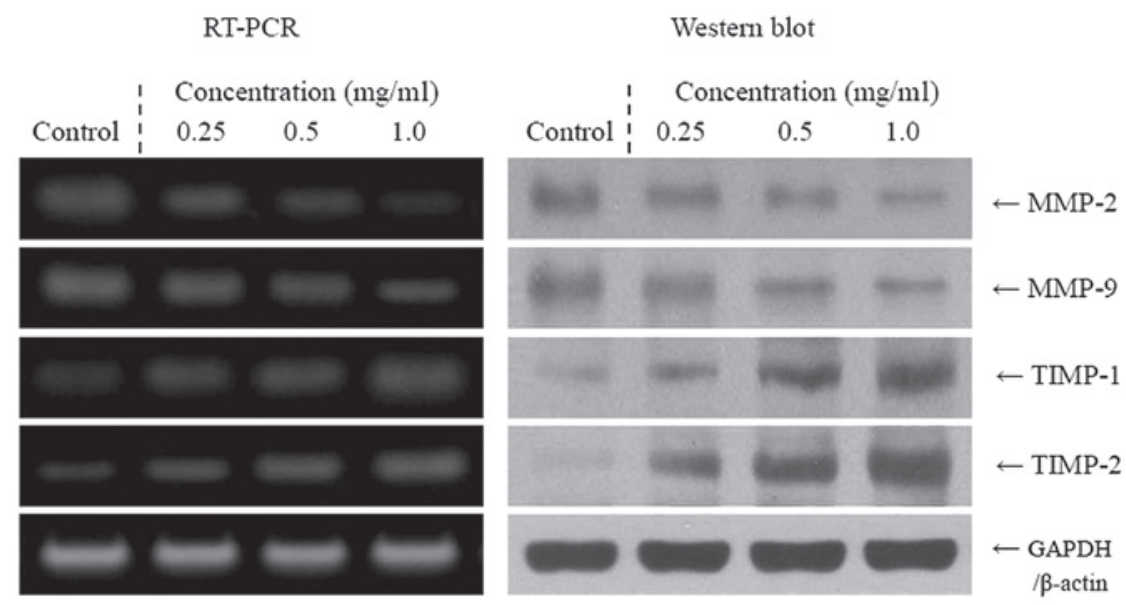

Figure 5. Effects of Cassia tora L. on the mRNA and protein expression of matrix metalloproteases (MMPs) and tissue inhibitors of metalloproteinases (TIMPs) in human tongue carcinoma TCA8113 cells.

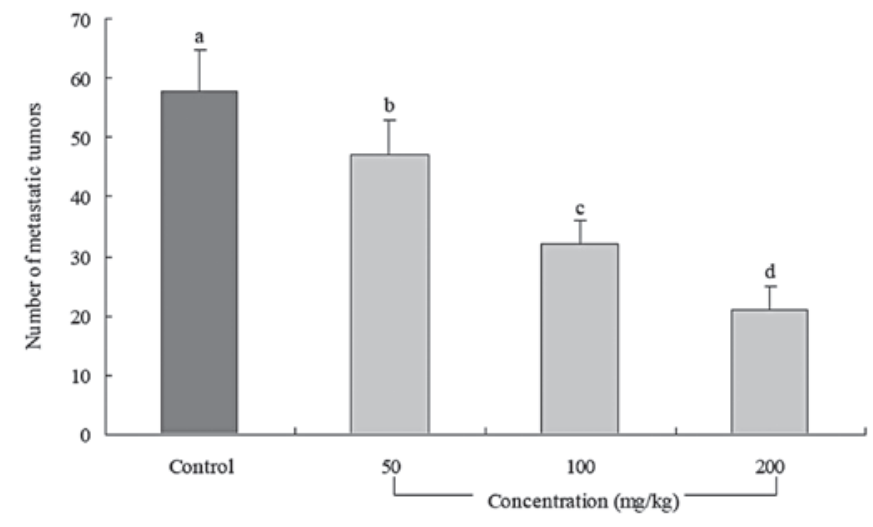

Figure 6. Inhibitory effect of Cassia tora L. on the metastasis of tumors produced by colon 26-M3.1 cells in Balb/c mice. The mice were administered the indicated dose of Cassia tora $\mathrm{L}$. by subcutaneous injection and then inoculated intravenously with $26 \mathrm{M}-3.1$ cells $\left(2.5 \times 10^{4}\right.$ cells/mouse $)$ after 2 days. Eight mice were assigned to each group 14 days after intravenous injection of the cancer cells. Lungs were removed and the number of lung tumor colonies were counted. ${ }^{\mathrm{a}-\mathrm{d}}$ Mean values with different letters over the bars are significantly different $(\mathrm{P}<0.05)$ according to Duncan's multiple range test.

that Cassia tora $\mathrm{L}$. induced apoptosis in the TCA8113 cells via a Bax- and Bcl-2-dependent pathway. The mRNA and protein expression levels of caspase-3 and -9 were very low in untreated control TCA8113 cells, but significantly increased following treatment of the cells with $1.0 \mathrm{mg} / \mathrm{ml}$ Cassia tora $\mathrm{L}$.
Caspase-3 and -9 mRNA and protein expression was gradually elevated by treatment with increased Cassia tora L. concentrations (Fig. 2). More specifically, the induction of apoptosis by Cassia tora L. was correlated with the upregulation of Bax, caspase-3 and -9 , and the downregulation of $\mathrm{Bcl}-2$, in terms of mRNA and protein expression. The effects of $1.0 \mathrm{mg} / \mathrm{ml}$ Cassia tora $\mathrm{L}$. were greater compared with those of 0.25 and $0.5 \mathrm{mg} / \mathrm{ml}$ Cassia tora $\mathrm{L}$.

Inflammation-related gene expression of $N F-\kappa B, I \kappa B-\alpha$, iNOS and $C O X-2$. We determined whether the anticancer effects of Cassia tora $\mathrm{L}$. were correlated with the inhibition of $\mathrm{NF}-\kappa \mathrm{B}$, I $\mathrm{B}-\alpha$, iNOS and COX-2 gene expression. As demonstrated in Fig. 3, mRNA and protein expression of NF- $\kappa \mathrm{B}$ and $\mathrm{I} \kappa \mathrm{B}-\alpha$ were reduced in TCA8113 cells treated with $1.0 \mathrm{mg} / \mathrm{ml}$ Cassia tora $\mathrm{L}$. solution. Cassia tora L. significantly modulated the expression of genes associated with inflammation. The mRNA and protein expression of NF- $\kappa \mathrm{B}$ decreased while I $\kappa \mathrm{B}-\alpha$ mRNA levels increased. Additionally, the mRNA and protein expression of COX-2 and iNOS gradually decreased in the presence of the Cassia tora L., depending on the concentration (Fig. 4). Our findings indicate that Cassia tora L. may help to prevent cancer in the early stages by increasing anti-inflammatory activities. Overall, the results of this experiment demonstrate that the higher concentration of Cassia tora L. had a stronger anti-inflammatory effect on the tongue carcinoma cells than the lower concentrations tested. 
Metastasis-related MMP and TIMP gene expression. RT-PCR and western blot analyses were conducted to determine whether the anti-metastatic effect of Cassia tora $\mathrm{L}$. was due to gene regulation of metastatic mediators, specifically MMPs (MMP-2 and -9) and TIMPs (TIMP-1 and -2), in TCA8113 cells. As demonstrated in Fig. 5, $1.0 \mathrm{mg} / \mathrm{ml}$ Cassia tora L. significantly decreased the mRNA and protein expressions of MMP-2 and -9, while it increased the expression of TIMP-1 and -2 . These changes in TIMP and MMP expression resulting from Cassia tora L. treatment effectively led to metastatic inhibition in vitro. Our results also demonstrated that the higher concentration of Cassia tora L. had a stronger anti-metastatic activity than the lower concentrations of Cassia tora L. tested.

In vivo anti-metastatic effect of Cassia tora L. Prophylactic inhibition of tumor metastasis by Cassia tora L. was evaluated using an experimental mouse metastasis model (Fig. 6). All mice treated with Cassia tora L. had significantly fewer lung metastatic colonies compared with the control mice (number of metastatic tumors, 58 \pm 7 ; number in each group $=10 ; \mathrm{P}<0.05$ ). Cassia tora $\mathrm{L}$. was most effective at inhibiting lung metastasis at a concentration of $200 \mathrm{mg} / \mathrm{kg}$. This concentration (inhibi-

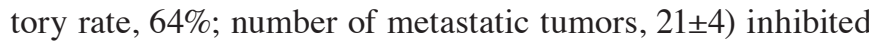
tumor formation and lung metastasis to a greater degree than the $100 \mathrm{mg} / \mathrm{kg}$ solution (inhibitory rate, 45\%; number of metastatic tumors, $32 \pm 4$ ) or the $50 \mathrm{mg} / \mathrm{kg}$ solution (inhibitory rate, $19 \%$; number of metastatic tumors, $47 \pm 6$ ) of Cassia tora $\mathrm{L}$.

\section{Discussion}

Although Cassia tora L. has been used as a medicine, scientific data concerning its effects is limited. Cassia tora L. has previously been demonstrated to have various therapeutic effects on numerous pathological conditions such as inflammation, aging and cancer $(3,4,6)$.

Apoptosis is a fundamental cellular event, and understanding its mechanisms of action will aid in the exploitation of this process in tumor diagnosis and therapy (22). In a healthy cell, the anti-apoptotic protein Bcl-2 is expressed on the outer mitochondrial membrane surface (23). As Bax and Bcl-2 genes are mainly expressed during apoptosis, we determined that these genes regulate apoptotic activity. Apoptosis results from the activation of caspase family members that act as aspartate-specific proteases (24). Caspases form a proteolytic network within the cell whereby upstream initiator caspases (such as caspase-9) are activated early on in the apoptotic process and in turn activate other downstream caspases (such as caspase-3). Cytochrome $c$ and procaspase-9 processing are highly dependent on caspase-3, placing this caspase in a central position as a regulator of essential apoptotic pathways in cancer cells (25). Caspase-3 has also been demonstrated to be involved in the amplification of apoptotic signals by cleaving Bcl-2 (26).

Additionally, anticancer mechanisms underlying the effect of Cassia tora L. on human cancer cells involve the induction of apoptosis by increasing the number of apoptotic bodies, regulating the mRNA and protein expression of Bax and $\mathrm{Bcl}-2$, and promoting anti-inflammatory effects by downregulating iNOS and COX-2 gene expression. COX-2 has been suggested to be important in colon carcinogenesis, while NOS, along with iNOS, may be a good target for the chemoprevention of colon cancer (27). NF- $\kappa \mathrm{B}$ is one of the most ubiquitous transcription factors, and it regulates the expression of genes required for cellular proliferation, inflammatory responses and cell adhesion (28). NF- $\mathrm{NB}$ is present in the cytosol where it is bound to the inhibitory protein, $\mathrm{I} \kappa \mathrm{B}$. Following its induction by a variety of agents, NF- $\kappa \mathrm{B}$ is released from I $\mathrm{B}$ and translocates to the nucleus where it binds to the $\kappa \mathrm{B}$ binding sites in the promoter regions of target genes (29). These mechanisms may be involved in the anticancer effects of Cassia tora L. in tongue carcinoma cells. Based on the results of the MTT assay and the expression patterns of pro-apoptotic genes observed in the present study, we conclude that cancer cells treated with Cassia tora L. underwent apoptosis. The anticancer effects of Cassia tora L. in JTC-26 human cervical cancer cells were evaluated in a previous study by an MTT assay and RT-PCR or western blot analysis, and were similar to our findings (6).

Metastasis is defined as the spread of cancer cells from one organ or area to an adjacent organ or another location $(30,31)$. Malignant tumor cells are considered to have the capacity to metastasize. Cancer occurs when the cells in a tissue have been genetically damaged in a progressive manner, resulting in cancer stem cells that possess a malignant phenotype. When the tumor cells have come to rest in another site, they penetrate the vessel walls, continue to multiply and eventually form another tumor.

MMPs, a family of zinc-dependent endopeptidases, are important in tumorigenesis and metastasis. MMPs are able to cleave almost all extracellular matrix (ECM) substrates. Degradation of the ECM is a key event in tumor progression, invasion and metastasis (32). Among the MMP family members, MMP-2 and -9 are important molecules for cancer invasion $(33,34)$, and are highly expressed in breast and colon cancer cells (35-37). Inhibition of MMP activity is useful for controlling tumorigenesis and metastasis (38). TIMPs are naturally occurring inhibitors of MMPs which prevent catalytic activity by binding to activated MMPs, thereby blocking breakdown of the ECM (39). Disturbances in the ratio between MMPs and TIMPs have been observed during tumorigenesis (40). Maintaining the balance between MMPs and TIMPs, or increasing TIMP activity, are useful ways to control tumor metastasis (41). Experimental evidence demonstrating the role of MMPs in metastasis has been obtained by in vitro invasion assays and in vivo xenograft metastasis experiments.

MMP-2 and -9 are key factors in cancer cell invasion and metastasis both in vivo and in vitro (42). Spontaneous and experimental metastasis to the liver is decreased in mice overexpressing TIMP1, and increased in mice expressing antisense TIMP-1 mRNA (43). Ectopic overexpression of TIMP-1 in the brain of transgenic mice also reduces experimental metastasis to the brain (44). In particular, MMP-2 and -9 are important for tumor invasion and angiogenesis. Thus, tumor metastasis may be inhibited by blocking MMP synthesis and activity (45). Colon 26-M3.1 carcinoma cells have been used to evaluate anti-metastasis effects in vivo (46).

In the current study, different concentrations of Cassia tora $\mathrm{L}$. were employed in our experiments. Cassia tora L. exerted anticancer and anti-metastatic effects on TCA8113 cells. All concentrations of Cassia tora $\mathrm{L}$. were found to have in vitro 
anti-metastasis effects based on the RT-PCR and protein analysis of MMP and TIMP gene expression, and also showed anti-metastasis effects in vivo. Further research is required to explain the mechanisms associated with these effects.

In summary, various in vitro experimental methods, including MTT, RT-PCR and western blot analysis, were employed to evaluate the anticancer effects of Cassia tora $\mathrm{L}$. A mouse model bearing tumors produced by 26-M3.1 colon carcinoma cells was used to study the in vivo effects of Cassia tora L. Overall, Cassia tora L. demonstrated potent in vitro and in vivo anticancer activities, particularly in combating in vivo tumor metastasis. The functional contents of Cassia tora L. are important for augmenting these anticancer effects. A high concentration of Cassia tora L. solution increased the anticancer properties in the present study. The active compounds resulting from Cassia tora L. require identification and evaluation in future studies.

\section{References}

1. Yen GC and Chung DY: Antioxidant effects of extracts from Cassia tora L. prepared under different degrees of roasting on the oxidative damage to biomolecules. J Agric Food Chem 47: 1326-1332, 1999.

2. Liu JZ, Lin X, Li XE, et al: Effect of protein and anthraquinone glucosides from Semen Cassia on learning and memory capacity and related substances of senile mice induced by D-galactose. China J Chinese Mater Med 32: 516-519, 2007 (In Chinese).

3. Lin DJ and Jin Z: Experimental study on protective effect of Semen Cassiae extract against acute liver injury. LiShiZhen Med Mater Med Res 17: 214-215, 2006.

4. Yen GC, Chen HW and Duh PD: Extraction and identification of an antioxidative component from Jue Ming Zi (Cassia tora L.). J Agric Food Chem 46: 820-824, 1998.

5. Kim SY, Kim JH, Kim SK, et al: Antioxidant activities of selected oriental herb extracts. J Am Oil Chem Soc 71, 633-640, 1994.

6. Hao YJ, Sang YL and Zhao YQ: Research progress of Jue-ming-zi Chinese Tradit Herbal Drugs 32: 858-859, 2001.

7. Qi GF: Cassia analysis of lipid-lowering active ingredients. Guang Ming Zhong Yi 26: 1569-1570, 2011.

8. Lowe SW and Lin AW: Apoptosis in cancer. Carcinogenesis 21: 485-495, 1999.

9. Kwon JI, Kim GY, Park KY, et al: Induction of apoptosis by linoleic acid is associated with the modulation of Bcl-2 family and Fas/FasL system and activation of caspases in AGS human gastric adenocarcinoma cells. J Med Food 11: 1-8, 2008.

10. Guerrero AD, Guerrero $M$ and Wang J: Delineation of the caspase-9 signaling cascade. Apoptosis 13: 177-186, 2008.

11. Tak PP and Firestein GS: NF- $\kappa$ B: a key role in inflammatory diseases. J Clin Invest 107: 7-11, 2001.

12. Balkwill $\mathrm{F}$ and Mantovani A: Inflammation and cancer: back to Virchow? Lancet 357: 539-545, 2001.

13. Mantovani A, Allavena P, Sica A, et al: Cancer-related inflammation. Nature 454: 436-444, 2008.

14. Itoh $\mathrm{Y}$ and Nagase H: Matrix metalloproteinases in cancer. Essays Biochem 38: 21-36, 2002.

15. Brew K, Dinakarpandian D and Nagase H: Tissue inhibitors of metalloproteinases: evolution, structure and function. Biochim Biophys Acta 1477: 267-83, 2000.

16. Woodhouse EC, Chuaqui RF and Liotta LA: General mechanisms of metastasis. Cancer 80: 1529-1537, 1997.

17. Chambers AF, Groom AC and MacDonald IC: Dissemination and growth of cancer cells in metastatic sites. Nat Rev Cancer 2: 563-572, 2002

18. Skehan P, Storeng R, Monks SA, et al: New colorimetric cytotoxicity assay for anticancer-drug screening. J Natl Cancer Inst 82: 1107-1112, 1990.

19. Bak SS, Kong CS, Rhee SH, et al: Effect of sulfur enriched young radish kimchi on the induction of apoptosis in AGS human gastric adenocarcinoma cells. J Food Sci Nutr 12: 79-83, 2007.

20. Choi YH, Lee SJ, Nguyen P, et al: Regulation of cyclin D1 by calpain protease. J Biol Chem 272: 28479-28484, 1997.
21. Jung KO, Park SY and Park KY: Longer aging time increases the anticancer and antimetastatic properties of doenjang. Nutrition 22: 539-545, 2006.

22. Milanezi F, Leitão D, Ricardo S, et al: Evaluation of HER2 in breast cancer: reality and expectations. Expert Opin Med Diagn 3: 607-620, 2009.

23. Chao DT and Korsmeyer SJ: Bcl-2 family: regulators of cell death. Annu Rev Immunol 16: 395-419, 1998.

24. Kidd VJ: Proteolytic activities that mediate apoptosis. Annu Rev Physiol 60: 533-573, 1998.

25. Blanc C, Deveraux QL, Krajewski S, et al: Caspase-3 is essential for procaspase-9 processing and cisplatin-induced apoptosis of MCF-7 breast cancer cells. Cancer Res 60: 4386-4390, 2000.

26. Kirsch DG, Doseff A, Chau BN, et al: Caspase-3-dependent cleavage of $\mathrm{Bcl}-2$ promotes release of cytochrome c. J Biol Chem 274: 21155-21161, 1999.

27. Delić R and Stefanović M: Optimal laboratory panel for predicting preeclampsia. J Maternal-Fetal Neonatal Med 23: 96-102, 2010

28. Baeuerle PA: IkappaB-NF-kappaB structures: at the interface of inflammation control. Cell 95: 729-731, 1998.

29. Sánchez-Pérez I, Benitah SA, Martinez-Gomariz M, et al: Cell stress and MEKK1-mediated c-Jun activation modulate NFkappaB activity and cell viability. Mol Biol Cell 13: 2933-2945, 2002.

30. Klein CA: Cancer. The metastasis cascade. Science 321: 1785-1787, 2008.

31. Chiang AC and Massagué J: Molecular basis of metastasis. New Engl J Med 359: 2814-2823, 2008

32. Vihinen P, Ala-aho R and Kähäri VM: Matrix metalloproteinase as therapeurtic targets in cancer. Curr Cancer Drug Targets 5: 203-220, 2005

33. Davies B, Waxman J, Wasan H, et al: Levels of matrix metalloproteinase in bladder cancer correlate with tumor grade and invasion. Cancer Res 53: 5365-5369, 1993.

34. Bogerieder T and Herlyn M: Axis of evil: molecular mechanism of cancer metastasis. Oncogene 22: 6524-6536, 2003.

35. Canning MT, Postovit LM, Clarke SH, et al: Oxygen-mediated regulation of gelatinase and tissue inhibitor of metalloproteinase-1 expression by invasive cells. Exp Cell Res 267: 88-94, 2001.

36. Bartsch JE, Staren ED and Appert HE: Matrix metalloproteinase expression in breast cancer. J Surg Res 110: 383-932, 2003

37. Zucker S and Vacirca J: Role of matrix metalloproteinases (MMPs) in colorectal cancer. Cancer Metastasis Rev 23: 101-117, 2004.

38. Chen PN, Chu SC, Chiou HL, et al: Mulberry anthjocyanins, cyaniding 3-rutinoside and cyaniding 3-glucoside, exhibited and inhibitory effect on the migration and invasion of a human lung cancer cell line. Cancer Lett 235: 248-259, 2006.

39. Uzui H, Harpf, A, Liu M, et al: Increased expression of memebrane type 3-matrix metalloproteinase in human atherosclerotic plaque: role of activated macrophage and inflammatory cytokines. Circulation 106: 3024-3030, 2002.

40. Lambert E, Dasse E, Haye B, et al: TIMPs as multifacial proteins. Crit Rev Oncol Hematol 49: 187-198, 2004.

41. Mysliwiec AG and Ornstein DL: Matrix metalloproteinases in colorectal cancer. Clin Colorectal Cancer 1: 208-219, 2002.

42. Kleiner DE and Stetler-Stevenson WG: Matrix metalloproteinases and tumor metastasis. Cancer Metastasis Rev 25: 9-34, 2006.

43. Krüger A, Fata JE and Khokha R: Altered tumor growth and metastasis of a T-cell lymphoma in TIMP-1 transgenic mice. Blood 90: 1993-2000, 1997.

44. Krüger A, Sanchez-Sweatman OH, Martin DC, et al: Host TIMP-1 overexpression confers resistance to experimental brain metastasis of a fibrosarcoma cell line. Oncogene 16: 2419-2423, 1998.

45. Shin DY, Kim GY, Kim JI, et al: Anti-invasive activity of diallyl disulfide through tightening of tight junctions and inhibition of matrix metalloproteinase activities in $\mathrm{LNCaP}$ prostate cancer cells. Toxicol In Vitro 24: 1569-1576, 2010.

46. Ha ES, Hwang SH, Shin KS, et al: Anti-metastatic activity of glycoprotein fractionated fromacanthopanax senticosus, involvement of NK-cell and macrophage activation. Arch Pharm Res 27: 217-224, 2004. 